Covered in: Web of Sciences (WOS); EBSCO; ERIH+; Google Scholar; Index Copernicus; Ideas RePeC; Econpapers; Socionet; CEEOL; Ulrich ProQuest; Cabell, Journalseek; Scipio; Philpapers; SHERPA/RoMEO repositories; KVK; WorldCat; CrossRef; CrossCheck

\section{Discussing with the Parents of High School Students: what do They Know about Drugs?}

\section{Alina COSTIN 1 , Alina Felicia ROMAN2}

${ }^{1}$ Associate Professor, "Aurel Vlaicu" University, Arad, Romania, costintalina@gmail.com

${ }^{2}$ Full Professor, "Aurel Vlaicu"

University, Arad, Romania, romanalinafelicia@yahoo.com
Abstract: The purpose of this paper was to investigate the differences in adolescents' parents' perception regarding the illegal drugs and drugs consumption among the adolescents. In order to carry out the research, a sociological questionnaire was developed, subsecrently to a qualitative information obtained by organizing 6 focus groups. The field survey was conducted in the municipality of Arad consisted of polling through the questionnaire technique a number of 204 families of students from 12 high schools. The results showed significant differences at thresholds of less than 0.05 between the group with high school and university degrees for variable knowledge and symptoms, between the parent group of Catholic religion and the other two groups (Orthodox and neo-Protestant) for knowledge and drug variables and also significant differences depending of the family structure. Furthermore, there were no significant differences between groups regarding the financial level of the families and the living environment.

During the research there was also followed the perspective of the parents of adolescents on the most used drugs among the students: in their opinion, the most used drugs are marijuana and ethnobotanical, with 120 , respectively 113 points, followed by ecstasy and cocaine, with 75 , respectively 64 points, and on the last places on consumption are the other types of drugs tested, with scores below 35 points. The result of Chi-square test showed that the values of $\chi^{2}$ are statistically significant for all drug categories, except for ethnobotanicals, in other words, the results can be generalized to the entire population.

Keywords: parents; high school students drug use; information; prevention.

How to cite: Costin, A., \& Roman, A.F. (2020).

Discussing with the Parents of High School Students: what do They Know about Drugs? Postmodern Openings, 11(1), 01-19. doi:10.18662/po/105 


\section{Introduction}

Substance use can be included among the "vices of the postmodern world" along with the Internet, venues and clubs, care rooms, etc., which make up a "narcissistic show" that Romanians have not participated in (Crăciun, 2006). Postmodernism as a cultural current promotes, among its ideologies that society is evolving more and more to be rational and knowledge is conditioned by context but also by other factors that facilitate the understanding and interpretation of social phenomena.

In this context, in which the idea of possessing the universal truth cannot be accepted, as there are no objective values or facts, I have chosen to question the aspects of a global phenomenon that knows a dynamic and complexity that is difficult to imagine. A pessimistic, yet very realistic view of the current social reality, has Alan Kirby (2009, p. 3, as cited by Muşat, 2015) who understands that we live in an autistic age due to the rupture between the real life individual.

In a world orchestrated by the pressures of globalization, we are trying to limit the phenomenon of drug use by intervening exactly at the source, in the family.

Drug use is a growing phenomenon with a fast dynamics and expansion which is difficult to control. The National Antidrug Strategy 2013-2020 starts with the elaboration of strategies from the existing reality, characterized by the diversification of the consumption behaviour, precociousness at the beginning of the consumption, the spread of the poly consumer model, and consumption reduction among genders.

Thus, it has become an undeniable truth that the subject of drug use can no longer be ignored. All European and national statistics and reports indicate a growing adherence to this phenomenon among young people: the producers are becoming more creative, they are getting closer to the target group by providing attractive products, diversifying the offer and adapting it to different age segments. Drugs seem to be the solution to different types of situations: acceptance in the group of friends, personal issues/conflicts solving, fun during free time or simply a real antidote for boredom. School, family, and the media are in front of a giant, of an incontestable challenge. We are challenged to convince young people that what they like, what gets them out of their daily lives, pleases their needs and answers to their questions is harmful, that it should not be consumed anymore. 


\section{Theoretical framework}

An effective prevention approach takes into account the risk factors of individual, social and family nature. American specialty literature emphasizes the imperative of diversifying prevention programmes due to the complexity of the consumption phenomenon. In this respect, prevention strategies are person oriented, centred on the group of equal peers and on the family. The theory of social learning (Bandura, 1963), the model of social development (Hawkins \& Catalano, 1992) and other newer theories assign the major responsibility in building the personality of the young person to the family. They should raise individuals who are resistant to temptation consumption through affective security that allows personal and social maturation, which helps the young man in the management of intra and interpersonal conflicts. Drug control, environmental configuration and person empowerment are the specific intervention directions within the antidrug strategy developed by the Ontario Dependency Research Foundation.

The prevention activity in Romania is largely undertaken by the drug prevention and counselling centres, which do not have the capacity and do not have sufficient human resources to efficiently cover the entire school population. However, the intervention of these centres is limited and is conditioned by the "material" to which it is addressed "- the resonance / impact of these actions varies according to what the family has generated, the competences acquired by the child in the family in terms of selfknowledge, self-control, maturation and vision of life in general. As the antidrug counsellors point out, it is easy to prevent where the student already has a positive background in terms of social skills. Of course, success in the prevention of consumption consists of a comprehensive approach which involves reducing risk factors and increasing protective factors, as underlined by adolescent risk behaviour theory (Jessor \& Jessor, 1977). Poor monitoring of adolescents by parents is associated with a higher risk of consumption (Steinberg, Fletcher, \& Darling, 1994) moreover, the literature supporting the importance of direct and indirect parents influence in drug use among adolescents is constantly increasing (Bahr, Hoffmann, \& Yang, 2005). The authoritarian style, characterized by imposing limits and applying sanctions leads to a decrease in the level of drug use (Baumrind, 1991). However, parents are considered credible sources of information, and young people at high risk of drug use are those who have not had anyone to talk to, according to the latest authors. 


\section{Research aim}

The prevention of drug use is not limited to information; the biggest consumers are pretty much informed; others are the mechanisms and factors that make the difference between occasional or zero consumption behaviour and constant consumption. Prevention is a "structured process that aims to optimize individual capacities and exercise their influence throughout life and in every aspect of one `s life" (Abraham, 2007, p. 5). The author shows that the structured nature of prevention is determined by the three dimensions that one should focus on and which are prevention objectives:

- drug control strategy;

- influence strategy for developing the individuals`competences;

- strategy of environmental configuration.

The first threshold, the first factor of protection when facing consumption risk is represented by the family.

The existing theoretical framework, specialized literature and the latest studies in the field of family, place a fundamental responsibility in the formation of the child's social competences so that he can manage properly, in favour of his health, the personal well-being, the challenges he will face. These social competences are built on the background of self-knowledge, the ability to manage emotions, a high level of self-control, a good selfimage, personal values, communication skills. But these traits are formed in the family, so the aim of this study is to identify the family "resources", its potential to prevent, to build a strong young person, resistant to temptations. What information do parents of high school students have about drugs? Can they recognize them? How do they relate to the topic of drug use? Did they approach this topic with their children? And how do they this? Have they sought information about drugs and the severity of their consequences, or discussed generalities? What do parents think about their child's relationship with drugs? What are the most effective strategies to encourage the child's resistance to drug use?

\section{Objectives}

In order to achieve an objective and sustainable drug prevention program among high school adolescents, the objectives considered in this study are to highlight the differences in parents' perceptions regarding illegal drugs and their consumption among adolescents. In this sense, the hypotheses of the study were formulated as follows: 


\section{Hypotheses}

1. There are differences in the level of drug knowledge of adolescent parents depending on the family structure: single parent and two parent family.

2. There are differences in the level of drug knowledge of adolescent parents depending on the level of education: primary school, high school and university studies.

3. There are differences regarding the level of knowledge about drugs of adolescent parents depending on the financial level of the family: poor, good and very good financial status.

4. There are differences in the level of knowledge about drugs of adolescent parents depending on the living environment: urban and rural environment.

5. There are differences in the level of drug knowledge of adolescent parents according to their religious affiliation: Orthodox, Catholic and Protestant.

6. There are differences in the opinion of adolescent parents about the most used drugs among students.

\section{Methodology}

\section{Participants}

The field survey was conducted between March and September 2019, at the level of Arad municipality by surveying a number of 204 families of high school teenagers, the sample of parents between the ages of 35 and 70 , with the average age $\mathrm{m}=44.66$ and a standard deviation $\mathrm{sd}=5.55$ years. At the sample level, 43 people were men (21.1\%) and 135 people were women $(66.2 \%)$. A total of 108 subjects $(52.9 \%)$ live in the urban area and 85 subjects $(41.7 \%)$ live in the rural area.

A percentage of $5.9 \%$, meaning 12 subjects, have a level of primary school education, a percentage of $61.8 \%$, meaning 126 subjects, have a high school education level and $29.9 \%$, meaning 61 subjects, have a level of university education. 123 of the participants stated that they have an Orthodox religious affiliation (60.3\%), 18 of the participants have a Catholic religion $(8.8 \%)$, and 55 subjects $(27 \%)$ are Protestant and neo-Protestant (Reformed, Baptist, Evangelical, Apostolic). Also, a number of 44 subjects $(21.6 \%)$ have a single-parent family structure and 147 subjects $(72.1 \%)$ have a two-parent family structure. 


\section{Instruments and method}

In order to carry out the research, a sociological questionnaire consisting of 29 items was developed, based on the data collected within a number of 6 focus groups. The questionnaire is structured in four main directions: information held by parents about illegal drugs and their use among adolescents, parents' perception of the drug problem, parents' perception of the child's attitude to drugs (the relationship and his her resilience to consumption) and the methods or opinion of parents regarding drug prevention and illegal drug use. In this article only the first questions of the questionnaire were used.

\section{Variables and design}

For testing the hypotheses we made a quasi-experimental, unifactorial, cross-sectional study, having as independent variables:

- hypothesis 1: level of education (with three modalities: primary school, high school and university studies),

- hypothesis 2: the financial level (with three modalities: poor, good and very good level),

- hypothesis 3: religious affiliation (with three modalities: Orthodox, Catholic and Protestant or neo-Protestant),

- hypothesis 4: family structure (with two modalities: single parent family and two-parent family),

- hypothesis 5: living environment (with two modalities: urban and rural area).

For hypothesis 6 we performed a descriptive design of the frequencies of the investigated drug types, testing the statistical significance with the Chi squared inferential test.

The dependent variables consisted of the scores of the subjects on the questionnaire items that explore the information held by the parents regarding drugs and substance use and which form the first part of the questionnaire as follows:

The variable knowledge consists of the scores obtained by subjects in items 1, 4 and 5 of the applied questionnaire, items that strictly evaluate the information of the parents related to drugs. The first item refers to alcohol and tobacco (as precursors of addictive behaviors and the use of illegal substances) and their belonging to the category of substances generally referred to as "drugs", with three possibilities of answer "Yes", "No" and "I don't know". Item 4 of the questionnaire evaluates the recognition of images illustrating different forms of presentation of illegal drugs (marijuana 
cigarette, Ecstasy pills, LDS stamps, white cocaine / heroin powder and hallucinogenic mushrooms) that respondents are asked to name to the extent where they are known. Item 5 of the questionnaire describes four types of symptoms that may or may not occur in the case of people who use or abuse substances in the drug category: fainting, aggression, delirium; hyperactivity and disfluency speaking; insomnia, laziness; changes in behavior and interest for activities and family. The Cronbach-alpha coefficient for the drug knowledge subscale of the questionnaire is good, with a value of 0.6 , achieved for the 3 questions (a total of 10 items) and a number of 203 cases.

The variable drugs is buildup of the scores obtained by the subjects in item 4 of the questionnaire and illustrates 5 forms of presentation of the most used drugs, coding taking into account the popular or street names of the substances: cannabis, marijuana, hashish, hemp, joint; MDMA with options Ecstasy, amphetamines, tablets, exciting, speed; LSD, with options acid, stamps, lysergic acid; heroin or cocaine, with junk, H, coke, snow; hallucinogenic mushrooms with options fungi, hallucinogenic, psilocybin. The Cronbach-alpha coefficient for this subscale of the questionnaire is very good, with the value of 0.81 , achieved on the 4 items and a number of 204 cases.

The variable symptom is composed of the scores obtained by the subjects in item 5 of the questionnaire, described above, with a coefficient of internal consistency alpha-Cronbach of 0.84 for 4 response variants and a number of 203 cases.

\section{Results}

1. For the purpose of testing the hypotheses we performed the descriptive statistical analysis for the studied variables on the whole sample (table 1.1.) as well as separately for the groups formed according to the level of education of the participants: primary school studies, $\mathrm{N}=12$, high school studies, $\mathrm{N}=152$, and university studies, $\mathrm{N}=61$ (table 1.2). Trends towards differences between the three levels of studies are observed, thus, a high score reflects a high level of knowledge about drugs and symptoms, in all cases the means for the group of participants with university studies being higher than the means of the other groups. 
Discussing with the Parents of High School Students: what do They Know ... Alina COSTIN, Alina Felicia ROMAN

Table 1.1. Descriptives and scattering statistical indices - knowledge about drugs

\begin{tabular}{lllll}
\hline \hline & & & & \\
& & Knowledge & Drugs & Simptoms \\
\hline $\mathrm{N}$ & Valid & 203 & 204 & 203 \\
& Missing & 1 & 0 & 1 \\
Mean & 5,4532 & 1,1029 & 1,3448 \\
Median & 5,0000 & 1,0000 & 1,0000 \\
Mode & 4,00 &, 00 & 1,00 \\
Std. Deviation & 2,08282 & 1,31838 &, 84976 \\
Minimum & 2,00 &, 00 &, 00 \\
Maximum & 10,00 & 4,00 & 4,00 \\
\hline \hline
\end{tabular}

Table 1.2. Descriptives and scattering statistical indices - knowledge according to studies' level

\begin{tabular}{lllllllllll}
\hline \hline & & \multicolumn{3}{l}{ Knowledge } & \multicolumn{2}{l}{ Drugs } & \multicolumn{3}{l}{ Simptoms } \\
\hline \hline & prim. & high. & univ. & prim. & high. & univ. & prim. & high. & univ. \\
\hline N Valid & 12 & 125 & 61 & 12 & 126 & 61 & 12 & 125 & 61 \\
Missing & 0 & 1 & 0 & 0 & 0 & 0 & 0 & 1 & 0 \\
Mean & 4,75 & 5,24 & 6,11 &, 66 & 1,08 & 1,29 & 1,08 & 1,22 & 1,63 \\
Median & 5,00 & 5,00 & 6,00 &, 00 &, 00 & 1,00 & 1,00 & 1,00 & 1,00 \\
Mode & 5,00 & 4,00 & 5,00 &, 00 &, 00 &, 00 & 1,00 & 1,00 & 1,00 \\
Std. & 1,71 & 2,02 & 2,16 & 1,23 & 1,34 & 1,29 &, 28 &, 76 & 1,01 \\
Deviation & 1,00 & 2,00 & 3,00 &, 00 &, 00 &, 00 & 1,00 &, 00 &, 00 \\
Minimum & 2,00 & & & & \\
Maximum & 9,00 & 10,00 & 10,00 & 4,00 & 4,00 & 4,00 & 2,00 & 4,00 & 4,00 \\
\hline \hline
\end{tabular}

Given the conditions for applying a parametric inferential test, we tested the statistical significance with Anova unifactorial. After calculating the $\mathrm{F}$ test (table 1.3) we obtained a coefficient $\mathrm{F}=4,483$ at a threshold sig. $=$ 0.012 for the knowledge variable, $\mathrm{F}=1,274$ at a threshold sig. $=0.282$ for the drug variable and $F=5,744$ at a threshold sig. $=0.004$ for the symptom variable, which means that the differences between the levels of education are statistically significant for knowledge and symptoms. 
Table 1.3. One-way ANOVA comparison - knowledge according to studies' level

\begin{tabular}{|c|c|c|c|c|c|c|}
\hline & & Sum of Squares & $\mathrm{df}$ & Mean Square & $\mathrm{F}$ & Sig. \\
\hline \multirow{3}{*}{ Knowledge } & Between Groups & 37,696 & 2 & 18,848 & 4,483 &, 012 \\
\hline & Within Groups & 819,759 & 195 & 4,204 & & \\
\hline & Total & 857,455 & 197 & & & \\
\hline \multirow{4}{*}{ Drugs } & Between Groups & 4,464 & 2 & 2,232 & 1,274 & ,282 \\
\hline & Within Groups & 343,395 & 196 & 1,752 & & \\
\hline & Total & 347,859 & 198 & & & \\
\hline & Between Groups & 7,936 & 2 & 3,968 & 5,744 & ,004 \\
\hline \multirow[t]{2}{*}{ Simptoms } & Within Groups & 134,710 & 195 & 691 & & \\
\hline & Total & 142,646 & 197 & & & \\
\hline
\end{tabular}

Since the value of the $\mathrm{F}$ test shows only a general influence of the differences in the level of knowledge about drugs and symptoms, we used the Scheffe post-hoc comparisons test to see between which levels of studies the differences are statistically significant. Considering the unequal distribution of subjects in the groups and the possibility of type 1 error due to the small number of subjects in the group with primary school studies, we will continue to refer only to the two groups made up of participants with high school and university studies. The results of the post-hoc comparisons demonstrate significant differences at the thresholds below 0.05 between the high school and university studies for the variables knowledge and symptoms, in other words, the level of studies of parents influences the level of knowledge about drugs and symptoms, parents with university degree will also have a higher level of general knowledge and information about drugs and the symptoms associated with substance use.

2. Next we performed the descriptive statistical analysis for the studied variables separately for the groups formed according to the religious affiliation of the participants: Orthodox religion, $\mathrm{N}=123$, Catholic religion, $\mathrm{N}=18$, and Protestant or neo-Protestant religion, $\mathrm{N}=55$ (table 1.4.). Trends towards differences between the three types of religions are observed, thus, a high score reflects a high level of knowledge about drugs and symptoms, in all cases the mean for the group of participants of Catholic religion is higher than the mean of the other groups. 
Discussing with the Parents of High School Students: what do They Know ... Alina COSTIN, Alina Felicia ROMAN

Table 1.4. Descriptives and scattering statistical indices - knowledge according to religious affiliation

\begin{tabular}{lllllllllll}
\hline \hline & \multicolumn{4}{c}{ Knowledge } & Drugs & \multicolumn{5}{l}{ Simptoms } \\
\hline \hline & Orthod. & Cat. & Prot. & Orthod. & Cat. & Prot. & Orthod. & Cat. & Prot. \\
\hline N Valid & 123 & 18 & 54 & 123 & 18 & 55 & 123 & 18 & 54 \\
Missing & 0 & 0 & 1 & 0 & 0 & 0 & 0 & 0 & 1 \\
Mean & 5,33 & 7,00 & 5,24 & 1,10 & 2,16 &, 85 & 1,20 & 1,55 & 1,50 \\
Median & 5,00 & 7,50 & 5,00 & 1,00 & 2,05 &, 00 & 1,00 & 1,00 & 1,00 \\
Mode & 4,00 & 9,00 & 4,00 &, 00 & 3,00 &, 00 & 1,00 & 1,00 & 1,00 \\
Std. & 2,03 & 2,11 & 2,05 & 1,31 & 1,50 & 1,14 &, 77 &, 78 &, 94 \\
Deviation & & & & & & & & & & \\
Minimum & 2,00 & 3,00 & 2,00 &, 00 &, 00 &, 00 &, 00 & 1,00 &, 00 \\
Maximum & 10,00 & 10,00 & 10,00 & 4,00 & 4,00 & 4,00 & 4,00 & 4,00 & 4,00 \\
\hline \hline
\end{tabular}

Having fulfilled the conditions for applying a parametric inferential test, we tested the statistical significance with Anova unifactorial. After calculating the $\mathrm{F}$ test (table 1.5.) we obtained a coefficient $\mathrm{F}=5,620$ at a threshold sig. $=0.004$ for the knowledge variable, $\mathrm{F}=7,092$ at a threshold sig. $=0.001$ for the drug variable and $\mathrm{F}=3,221$ at a threshold sig. $=0.042$ for the symptom variable, which means that the differences between the groups formed by religious affiliation are statistically significant for the three variables: knowledge, drugs and symptoms.

Table 1.5. One-way ANOVA comparison - knowledge according to religious affiliation

\begin{tabular}{lllllll}
\hline \hline & & Sum of Squares & df & Mean Square & F & Sig. \\
\hline \multirow{4}{*}{ Knowledge } & Between Groups & 47,258 & 2 & 23,629 & 5,620 &, 004 \\
& Within Groups & 807,204 & 192 & 4,204 & & \\
& Total & 854,462 & 194 & & & \\
\multirow{5}{*}{ Drugs } & Between Groups & 23,589 & 2 & 11,794 & $7,092,001$ \\
& Within Groups & 320,962 & 193 & 1,663 & & \\
& Total & 344,551 & 195 & & & \\
\multirow{5}{*}{ Simptoms } & Between Groups & 4,424 & 2 & 2,212 & 3,221 &, 042 \\
& Within Groups & 131,863 & 192,687 & & \\
& Total & 136,287 & 194 & & & \\
\hline \hline
\end{tabular}

Since the value of the $\mathrm{F}$ test shows only a general influence of the differences in the level of knowledge about drugs and symptoms, we used 
the Scheffe post-hoc comparisons test (Appendix 1.) to see between which religious affiliation groups the differences are statistically significant. Considering the uneven distribution of subjects in the groups and the possibility of type 1 error due to the small number of subjects in the Catholic religion group, the results of the post-hoc comparisons demonstrate significant differences at thresholds lower than 0.05 between the group of parents of Catholic religion and the other two groups for knowledge and drug variables, in other words, the religious affiliation of parents influences the level of knowledge about drugs, parents of Catholic religion having a higher level of knowledge and general information about drugs.

3. Next we performed the descriptive statistical analysis for the studied variables separately for the groups formed according to the level of living, evaluated by the financial status of the participants: poor living level, $\mathrm{N}=9$, good living level, $\mathrm{N}=177$, and very good living level, $\mathrm{N}=14$ (table 1.6.). Trends towards differences between the three groups are observed, thus a high score reflects a high level of knowledge about drugs and symptoms, in all cases the means for the group of participants with a good and very good standard of living being higher than the means of the group with a low standard of living.

Table 1.6. Descriptives and scattering statistical indices - knowledge according to life's standard

\begin{tabular}{|c|c|c|c|c|c|c|c|c|c|}
\hline & \multicolumn{3}{|c|}{ Knowledge } & \multicolumn{3}{|c|}{ Drugs } & \multicolumn{3}{|c|}{ Simptoms } \\
\hline & poor & good & $\begin{array}{l}\text { very } \\
\text { good }\end{array}$ & poor & good & $\begin{array}{l}\text { very } \\
\text { good }\end{array}$ & poor & good & $\begin{array}{l}\text { very } \\
\text { good }\end{array}$ \\
\hline Valid & 9 & 176 & 14 & 9 & 177 & 14 & 9 & 176 & 14 \\
\hline Missing & 0 & 1 & 1 & 0 & 0 & 0 & 0 & 1 & 1 \\
\hline Mean & 4,00 & 5,53 & 5,71 & ,33 & 1,15 & 1,28 & 1,00 & 1,35 & 1,42 \\
\hline Median & 4,00 & 5,00 & 5,50 &, 00 & 1,00 & 5,00 & 1,00 & 1,00 & 1,00 \\
\hline Mode & 3,00 & 4,00 & 3,00 & 00 &, 00 &, 00 & 1,00 & 1,00 & 1,00 \\
\hline $\begin{array}{l}\text { Std. } \\
\text { Deviation }\end{array}$ & 1,41 & 2,08 & 2,16 &, 70 & 1,32 & 1,54 &, 00 &, 87 & ,00 \\
\hline Minimum & 2,00 & 2,00 & 3,00 &, 00 & ,00 &, 00 & 1,00 &, 00 &, 00 \\
\hline Maximum & 6,00 & 10,00 & 9,00 & 2,00 & 4,00 & 4,00 & 1,00 & 4,00 & 3,00 \\
\hline
\end{tabular}

Given the conditions for applying a parametric inferential test, we tested the statistical significance with Anova unifactorial. After calculating the test F (table 1.7.) we obtained coefficients at statistically insignificant 
thresholds, greater than 0.05 , for all the three variables studied, therefore, considering the unequal distribution of the subjects in the groups and the possibility of occurrence of type 1 error, it can be said that the standard of living does not influence the knowledge and information about drugs and the symptoms associated with the consumption.

Table 1.7. One-way ANOVA comparison - knowledge according to life's standard

\begin{tabular}{lllllll}
\hline \hline & & Sum of Squares & df & Mean Square & F & Sig. \\
\hline \multirow{4}{*}{ Knowledge } & Between Groups & 21,110 & 2 & 10,555 & 2,461 &, 088 \\
& Within Groups & 840,579 & 196 & 4,289 & & \\
& Total & 861,688 & 198 & & & \\
\multirow{5}{*}{ Drugs } & Between Groups & 6,137 & 2 & 3,068 & 1,769 &, 173 \\
& Within Groups & 341,738 & 197 & 1,735 & & \\
& Total & 347,875 & 199 & & & \\
\multirow{5}{*}{ Simptoms } & Between Groups & 1,176 & 2 &, 588 &, 814 &, 445 \\
& Within Groups & 141,588 & 196 &, 722 & & \\
& Total & 142,764 & 198 & & & \\
\hline \hline
\end{tabular}

4. Next we performed the descriptive statistical analysis for the studied variables separately for the groups formed according to the family structure: single parent family, $\mathrm{N}=44$, and two-parent family, $\mathrm{N}=147$ (table 1.8.). Trends towards differences between the two types of families are observed, thus, a high score reflects a high level of knowledge about drugs and symptoms, the means for the group of participants with a single parent family being higher for the knowledge and drug variables, and lower for the variable symptoms.

Table 1.8. Descriptives and scattering statistical indices - knowledge according to the family structure

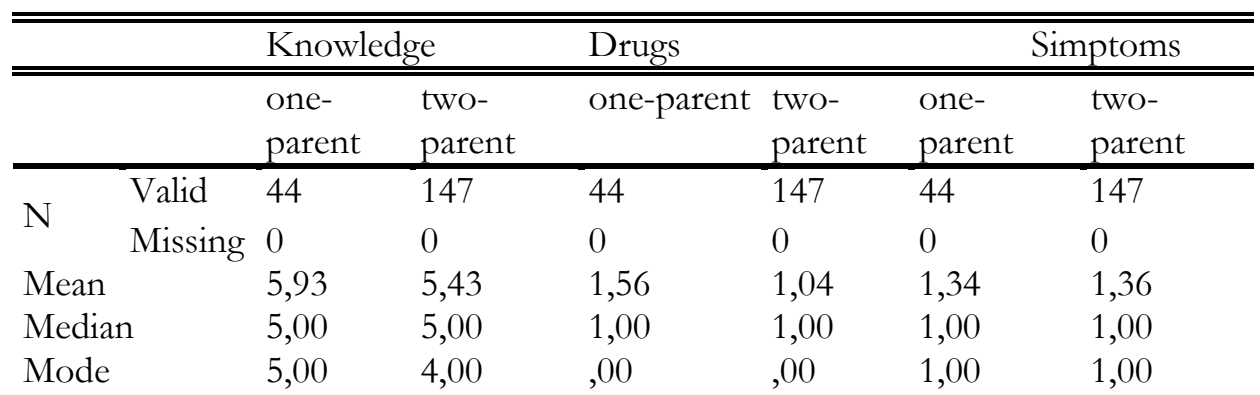




\begin{tabular}{lllllll} 
Std. Deviation & 2,16 & 2,05 & 1,56 & 1,23 &, 83 &, 85 \\
Minimum & 3,00 & 2,00 &, 00 &, 00 &, 00 &, 00 \\
Maximum & 10,00 & 10,00 & 4,00 & 4,00 & 4,00 & 4,00 \\
\hline \hline
\end{tabular}

Having met the conditions for applying a parametric inferential test, we tested the statistical significance with the $\mathrm{t}$ (student) test for independent samples. After calculating the $t$ test (table 1.9.) we obtained a coefficient $t=$ 2.328 at a threshold sig. $=0.21$ for the drug variable, and coefficients at statistically insignificant thresholds, greater than 0.05 , for the knowledge and symptoms variables, which means that the differences between the groups formed according to the family structure are statistically significant in terms of drug knowledge, so it can be said that single parent families have a richer knowledge about drug types.

Table 1.9. Test t comparison knowledge according to family's structure

\begin{tabular}{|c|c|c|c|c|c|c|c|c|c|c|}
\hline & \multicolumn{2}{|c|}{$\begin{array}{c}\text { Levene's } \\
\text { Test for } \\
\text { Equality of } \\
\text { Variances }\end{array}$} & \multicolumn{7}{|c|}{ t-test for Equality of Means } \\
\hline & & \multirow[t]{2}{*}{$\mathrm{F}$} & \multirow[t]{2}{*}{$\begin{array}{c}\text { Sig } \\
\text {. }\end{array}$} & \multirow[t]{2}{*}{$\mathrm{t}$} & \multirow[t]{2}{*}{$\mathrm{df}$} & \multirow{2}{*}{$\begin{array}{l}\text { Sig. } \\
(2- \\
\text { taile } \\
\text { d) }\end{array}$} & \multirow[t]{2}{*}{$\begin{array}{c}\text { Mean } \\
\text { Differen } \\
\text { ce }\end{array}$} & \multirow{2}{*}{$\begin{array}{c}\text { Std. } \\
\text { Error } \\
\text { Differen } \\
\text { ce }\end{array}$} & \multicolumn{2}{|c|}{$\begin{array}{c}95 \% \\
\text { Confidence } \\
\text { Interval of the } \\
\text { Difference }\end{array}$} \\
\hline & & & & & & & & & $\begin{array}{c}\text { Low } \\
\text { er }\end{array}$ & Upper \\
\hline \multirow[t]{2}{*}{$\begin{array}{l}\text { Knowled } \\
\text { ge }\end{array}$} & $\begin{array}{l}\text { Equal } \\
\text { varianc } \\
\text { es } \\
\text { assume } \\
\text { d }\end{array}$ & ,551 & $\begin{array}{l}, 45 \\
9\end{array}$ & $\begin{array}{l}1,38 \\
8\end{array}$ & 189 & ,167 & ,49644 & ,35770 & $\begin{array}{l}- \\
, 2091 \\
6\end{array}$ & $\begin{array}{l}1,202 \\
05\end{array}$ \\
\hline & $\begin{array}{l}\text { Equal } \\
\text { varianc } \\
\text { es not } \\
\text { assume } \\
\text { d }\end{array}$ & & & $\begin{array}{l}1,35 \\
1\end{array}$ & $\begin{array}{l}68,03 \\
0\end{array}$ & ,181 & ,49644 & ,36733 & $\begin{array}{l}- \\
2365 \\
4\end{array}$ & $\begin{array}{l}1,229 \\
43\end{array}$ \\
\hline \multirow[t]{2}{*}{ Drugs } & $\begin{array}{l}\text { Equal } \\
\text { varianc } \\
\text { es } \\
\text { assume } \\
\text { d }\end{array}$ & $\begin{array}{l}10,08 \\
6\end{array}$ & $\begin{array}{l}\text {,00 } \\
2\end{array}$ & $\begin{array}{l}2,32 \\
8\end{array}$ & 189 & ,021 & ,52737 & 22657 & $\begin{array}{l}, 0804 \\
4\end{array}$ & $\begin{array}{l}\text {,9743 } \\
0\end{array}$ \\
\hline & $\begin{array}{l}\text { Equal } \\
\text { varianc } \\
\text { es not } \\
\text { assume } \\
\text { d }\end{array}$ & & & $\begin{array}{l}2,05 \\
6\end{array}$ & $\begin{array}{l}60,08 \\
4\end{array}$ & ,044 & ,52737 & ,25654 & $\begin{array}{l}, 0142 \\
2\end{array}$ & $\begin{array}{l}1,040 \\
51\end{array}$ \\
\hline
\end{tabular}


Discussing with the Parents of High School Students: what do They Know ... Alina COSTIN, Alina Felicia ROMAN

\begin{tabular}{|c|c|c|c|c|c|c|c|c|c|c|}
\hline \multirow[t]{2}{*}{$\begin{array}{l}\text { Simptom } \\
\mathrm{s}\end{array}$} & $\begin{array}{l}\text { Equal } \\
\text { varianc } \\
\text { es } \\
\text { assume } \\
\text { d } \\
\end{array}$ & ,030 & $\begin{array}{l}, 86 \\
3\end{array}$ & , 134 & 189 & ,894 &,- 01964 & ,14672 & $\begin{array}{l}- \\
\text {,3090 } \\
5\end{array}$ & $\begin{array}{l}, 2697 \\
8\end{array}$ \\
\hline & $\begin{array}{l}\text { Equal } \\
\text { varianc } \\
\text { es not } \\
\text { assume } \\
\text { d }\end{array}$ & & & $-\overline{-}$ & $\begin{array}{l}72,56 \\
0\end{array}$ & ,892 &,- 01964 & 14430 & $\begin{array}{l}- \\
, 3072 \\
6\end{array}$ & $\begin{array}{l}, 2679 \\
9\end{array}$ \\
\hline
\end{tabular}

5. Next we performed the descriptive statistical analysis for the studied variables separately for the groups formed according to the family living environment: urban area, $\mathrm{N}=108$, and rural area, $\mathrm{N}=86$ (table 1.10.). In a summary analysis of the means, slight tendencies towards differences between the two types of living environment are observed for all the three variables studied.

Table 1.10. Descriptives and scattering statistical indices - knowledge according to environment

\begin{tabular}{|c|c|c|c|c|c|c|c|}
\hline & & \multicolumn{2}{|c|}{ Knowledge } & \multicolumn{2}{|l|}{ Drugs } & \multicolumn{2}{|c|}{ Simptoms } \\
\hline & & urban & rural & urban & rural & urban & rural \\
\hline \multirow{2}{*}{$\mathrm{N}$} & Valid & 107 & 86 & 108 & 86 & 107 & 86 \\
\hline & Missing & 1 & 0 & 0 & 0 & 1 & 0 \\
\hline \multicolumn{2}{|c|}{ Mean } & 5,59 & 5,36 & 1,21 & 1,06 & 1,30 & 1,34 \\
\hline \multicolumn{2}{|c|}{ Median } & 5,00 & 5,00 & 1,00 &, 50 & 1,00 & 1,00 \\
\hline \multicolumn{2}{|c|}{ Mode } & 4,00 & 4,00 &, 00 &, 00 & 1,00 & 1,00 \\
\hline \multicolumn{2}{|c|}{ Std. Deviation } & 2,20 & 1,94 & 1,32 & 1,33 & 85 &, 80 \\
\hline \multicolumn{2}{|c|}{ Minimum } & 2,00 & 2,00 &, 00 &, 00 &, 00 & 00 \\
\hline \multicolumn{2}{|c|}{ Maximum } & 10,00 & 10,00 & 4,00 & 4,00 & 4,00 & 4,00 \\
\hline
\end{tabular}

Having met the conditions for applying a parametric inferential test, we tested the statistical significance with the $t$ (student) test for independent samples. After calculating the t test (table 1.11.) we obtained coefficients at statistically insignificant thresholds, greater than 0.05 , for all three variables, which means that the differences between the groups formed according to the living environment are not statistically significant in regarding the knowledge of drugs and associated symptoms, therefore it can be said that the living environment does not influence the level of knowledge and information about drugs and symptoms. 
Table 1.11. Test t comparison - knowledge according to environment

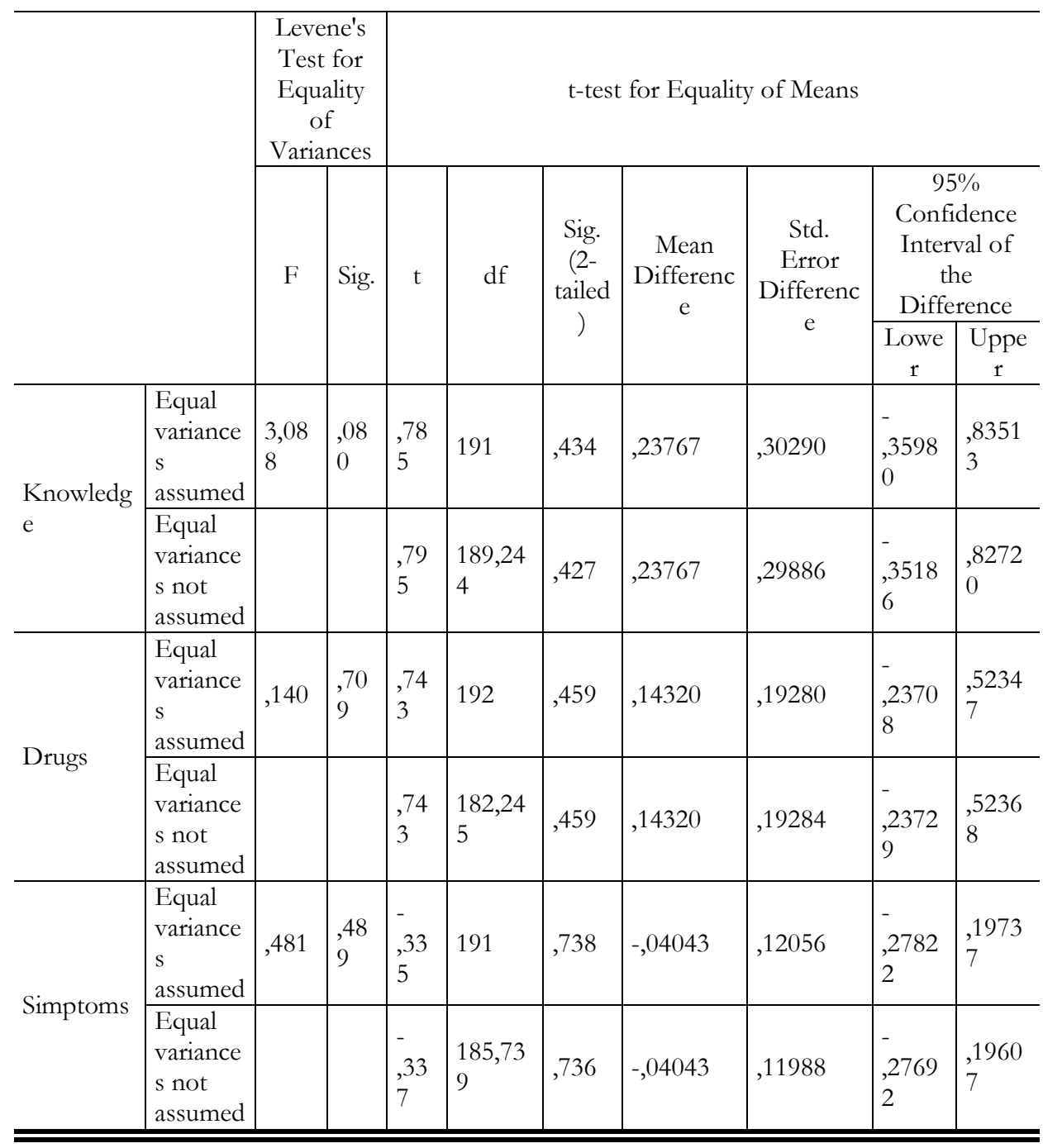

6. During the research we also followed the perspective of the parents of adolescents on the most used drugs among the students, aspect evaluated with item 6 of the questionnaire. In table 1.12. it can be seen that, in the opinion of the parents, the first places are taken by marijuana and ethnobotanical, with 120 , respectively 113 points, followed by ecstasy and cocaine, with 75 and 64 points respectively, and on the last places on consumption are the other types of drugs tested, with scores below 35 points (figure 1.2). 
In order to verify the statistical significance of the differences of means obtained by each category, we took into account the asymmetric distributions and the unequal dispersions of the result sets and applied the nonparametric Chi-square inferential test (Appendix 1). The values of $\chi^{2}$ are statistically significant, at thresholds sig. $\leq 0.05$ for all categories of drugs, except for ethnobotanicals, so the results can be generalized to the entire population.

Table 1.12. Hierarchy of the most used drugs among the students

\begin{tabular}{llllllll}
\hline \hline Nume & $\mathrm{N}$ & Mean & Median & Mode & $\begin{array}{l}\text { Std. } \\
\text { Deviation }\end{array}$ & $\begin{array}{l}\text { Chi } \\
\text { square }\end{array}$ & Sig. \\
\hline Marijuana & 120,00 &, 59 & 1,00 & 1,00 &, 49 & 6,744 &, 009 \\
Etnobotanics & 113,00 &, 55 & 1,00 & 1,00 &, 49 & 2,606 &, 106 \\
Ecstasy & 75,00 &, 36 &, 00 &, 00 &, 48 & 13,837 &, 000 \\
Cocaine & 64,00 &, 31 &, 00 &, 00 &, 46 & 27,709 &, 000 \\
Heroin & 35,00 &, 17 &, 00 &, 00 &, 37 & 87,138 &, 000 \\
Amfetamins & 30,00 &, 14 &, 00 &, 00 &, 35 & $100,734,000$ \\
LSD & 23,00 &, 11 &, 00 &, 00 &, 31 & 121,424 &, 000 \\
Mushrooms & 10,00 &, 04 &, 00 &, 00 &, 21 & 164,970 &, 000 \\
\hline \hline
\end{tabular}

\section{Conclusions}

The purpose of this paper was to highlight differences in parents' perceptions regarding illegal drugs and their use among adolescents. To achieve this purpose, 6 hypotheses were formulated that test the differences regarding the level of knowledge about drugs and the symptoms associated with consumption according to the family structure, the level of education, the financial level, the living environment and their religious affiliation, as well as the parents' opinion about the most commonly used illegal drugs.

The field survey was conducted at the level of Arad municipality by surveying a number of 204 families of high school teenagers, the sample of parents between the ages of 35 and 70, with the average age $\mathrm{m}=44.66$ and a standard deviation sd $=5.55$ years. The instrument used in the research consisted of a sociological questionnaire consisting of 29 items, developed from the data collected within a number of 6 focus groups.

Following the descriptive analysis, there were evidenced tendencies towards differences between the three groups of subjects formed according to the level of studies: primary school, high school and university. Thus, given that a high score reflects a high level of knowledge about illegal drugs and the symptoms associated with drug use, in all cases the means for the 
group of participants with university studies were higher than the means of the other groups. Following the inferential testing with Anova unifactorial, statistically significant differences were revealed between groups for the variables knowledge and symptoms. The results of the post-hoc comparisons showed significant differences at thresholds below 0.05 between the high school and university studies for the variables knowledge and symptoms, in other words, the level of parental studies influences the level of knowledge about drugs and symptoms, the parents with university degree will also have a higher level of general knowledge and information about drugs and the symptoms associated with substance use. Furthermore, the descriptive statistical analysis highlighted tendencies towards differences between the three groups of subjects formed according to the religious affiliation of the participants: Orthodox religion, Catholic religion and Protestant and neo-Protestant religion, the group of participants of Catholic religion obtaining higher means than the other two groups. Following the inferential testing with Anova unifactorial, statistically significant differences were revealed between groups for all three variables: knowledge, drugs and symptoms. The results of the post-hoc comparisons showed significant differences at thresholds lower than 0.05 between the Catholic parent group and the other two groups for the knowledge and drug variables, in other words, the religious affiliation of the parents influences the level of knowledge about drugs, the parents of Catholic religion having a higher level of knowledge and general information about drugs.

Regarding the analysis performed for the groups of subjects made up according to the standard of living, evaluated by the financial status of the participants as: poor living level, good living level, and very good living level, the results highlighted trends towards differences between those three groups, in all cases the means for the group of participants with a good and very good standard of living being higher than the means of the group with a low standard of living. Comparisons with Anova unifactorial have shown statistically insignificant differences between groups, thus, it can be said that the standard of living does not influence the knowledge and information on drugs and the symptoms associated with the consumption.

The mean differences observed in the case of the descriptive analysis on the groups formed according to the family structure, single parent and two-parent family, showed higher tendencies for the group of participants with single parent family for the knowledge and drug variables, and smaller for the symptom variable. Following the inferential test with the t-test (student) for independent samples, statistically significant differences were detected between groups for the drug variable, so it can be said that single- 
parent families have richer knowledge about drug types.Moreover, the descriptive statistical analysis showed trends towards differences between the groups formed according to the family living environment: urban and rural environment, but by applying the t test for independent samples it was shown that these differences are not statistically significant.

In the research we also followed the perspective of adolescent parents on the most used drugs among students, thus, in the parents' opinion, the first places were marijuana and ethnobotanical, with 120, respectively 113 points, followed by ecstasy and cocaine, with 75, respectively 64 points, and on the last places of consumption were classified the other types of drugs tested, with scores below 35 points, results confirmed by the Chi-square test values for all categories of drugs, except of drugs etnobotanics.

\section{The limits}

The limits of the study are determined by the sample represented by the 204 parents. However, their survey allowed us to draw some conclusions regarding the level of preparation of parents on the issue of drug prevention.

\section{Acknowledgement}

We would like to thank the high schools participating in the study, the school inspectorate and the school counselors who facilitated the meetings with the parents.

\section{References}

Abraham, P. (Coord.). (2007). Ghid de prevenire a consumului de droguri în rândul adolescenților şi tinerilor [Guidelines for the prevention of drug use among adolescents and young people]. Retrieved from

http://masterdroguri.ro/wpcontent/uploads/2015/03/ghid de prevenire a consumului de droguri. pdf

Bahr, S. J., Hoffmann, J. P., \& Yang, X. J. (2005). Parental and peer influences on the risk of adolescent drug use. Primary Prevent, 26(6), 529-551. doi:10.1007/s10935-005-0014-8

Bandura, A. (1963). Social learning and personality development. New York, USA: Holt, Rinehart, and Winston. 
Baumrind, D. (1991). The influence of parenting style on adolescent competence and substance use. The Journal of Early Adolescence, 11(1), 56-95. doi:10.1177/0272431691111004

Crăciun, G. (2006). Viciile lumii postmoderne [The vices of the postmodern world]. Bucharest, Romania: Tracus Arte.

Hawkins, J. D., \& Catalano, R. F. (1992). The Jossey-Bass social and behavioral science series and The Jossey-Bass education series. Communities that care: Action for drug abuse prevention. Retrieved from https://psycnet.apa.org/record/1992$\underline{98370-000}$

Jessor, R., \& Jessor, S. L. (1977). Problem behavior and psychosocial development: A longitudinal study of youth. New York, USA: Academic Press.

Kirby, A. (2009). Digimodernism: How new technologies dismantle the postmodern and reconfigure our culture. New York, USA: Continuum.

Muşat, C. (2015). Postmodernismul - un concept problematic depăşit [Postmodernism - an outdated problematic concept]. Retrieved from https://www.academia.edu/35592881/Postmodernismul_un_concept_pro blematic dep $\% \mathrm{C} 4 \% 83 \% \mathrm{C} 5 \% 9$ Fit

Steinberg, L., Fletcher, A., \& Darling, N. (1994). Parental monitoring and peer influences on adolescent substance use. Pediatrics Journal, 93(6), 1060-1064. doi:10.1017/cbo9780511527906.016 